\title{
Autonomy, intimate partner violence, and maternal health-seeking behavior: Findings from mixed-methods analysis in Nigeria
}

\author{
Pooja Sripad \\ Population Council \\ Charity Ndwiga \\ Population Council \\ Charlotte E. Warren \\ Population Council
}

Follow this and additional works at: https://knowledgecommons.popcouncil.org/departments_sbsr-rh

Part of the Demography, Population, and Ecology Commons, Domestic and Intimate Partner Violence Commons, Family, Life Course, and Society Commons, Gender and Sexuality Commons, International Public Health Commons, Maternal and Child Health Commons, and the Medicine and Health Commons How does access to this work benefit you? Let us know!

\section{Recommended Citation}

Sripad, Pooja, Charity Ndwiga, and Charlotte E. Warren. 2019. "Autonomy, intimate partner violence, and maternal health-seeking behavior: Findings from mixed-methods analysis in Nigeria," Ending Eclampsia Country Brief. Washington, DC: Population Council. 
Autonomy, Intimate Partner Violence, and Maternal Health-Seeking Behavior: Findings from MixedMethods Analysis in Nigeria

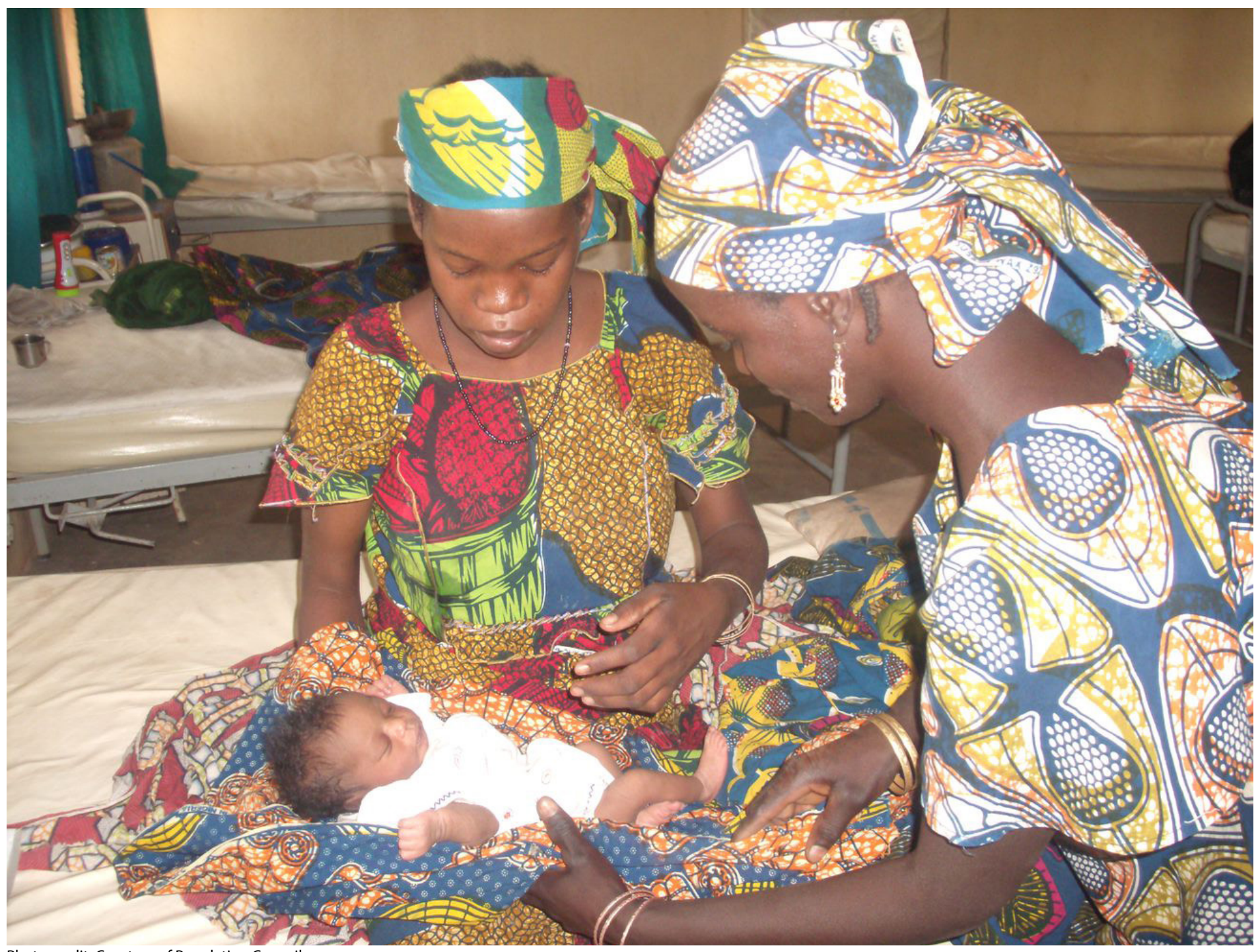

Photo credit: Courtesy of Population Council

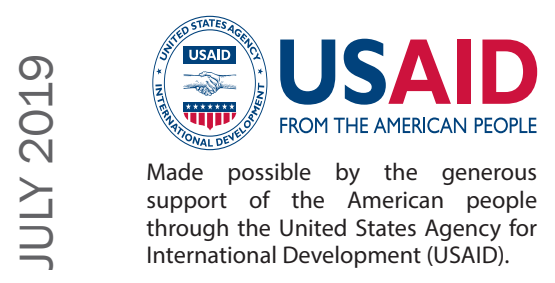

The Population Council conducts research and delivers solutions that improve lives around the world. Big ideas supported by evidence: It's our model for global change. popcouncil.org

(c) 2019 The Population Council, Inc.

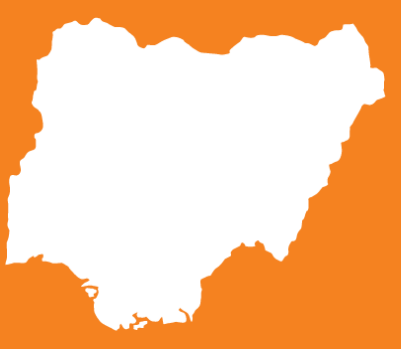




\section{BACKGROUND}

Gendered norms and discriminatory practices often limit women's decision-making power, which over time can lead to social norms that systematically subordinate women.

Aspects of empowerment, a multi-faceted construct, were explored in a global evaluation of Demographic and Health Survey (DHS) data, that measured how gendered social norms influenced maternal health-seeking behaviors. Analysis specifically explored associations of women's autonomy and acceptability of intimate partner violence against women (IPVAW) on antenatal care (ANC) use and facility delivery in 63 low- and middle-income countries. Service utilization is positively associated with increased autonomy and negatively associated with increased acceptability of IPVAW, but variability exists across countries and regions (1). There is need to explore complexities of gender in specific contexts.

In Nigeria, maternal health-seeking behaviors are influenced by numerous interrelated factors. Little research exists on how gender dynamics and norms, including acceptability of various forms of IPVAW, may influence women's decision-making autonomy, health-seeking behavior, and overall well-being.

The purpose of this study was to explore the relationship between women's autonomy and acceptability of IPVAW and two primary maternal health care utilization outcomes: ANC use and facility delivery.

This brief highlights quantitative and qualitative findings on the relationship between women's autonomy and IPVAW acceptability and maternal health seeking behaviors in Nigeria.

\section{METHODS}

We applied a mixed methods approach to explore gender dynamics drawing on a secondary analysis of aggregate DHS data in Nigeria from 2008 to 2013, and 29 in-depth interviews with women who had experienced and survived pre-eclampsia in Bauchi, Cross River, Ebonyi, Katsina, Kogi, Ondo, and Sokoto states between 2014 and 2015.

Scales developed for women's autonomy (6-item) and acceptability of IPVAW (5-item) indicate women's contribution to decision-making around various aspects of their lives and accepting attitudes toward a husband beating his wife for different reasons.

Multivariable logistic regressions estimate associations between these scores and the primary outcomes, controlling for age, wealth, education, marital status, birth order, child sex, urban/rural residence and quality of care at the individual level and average wealth and education attainment at the cluster level.

Qualitative analyses involved transcription and translation of interviews, applying an inductivelyderived codebook using NVivo, and triangulating findings from the tertiary hospital with DHS results.

\section{RESULTS}

Combined DHS data from the 2008 and 2013 surveys yielded a sample of 35,332 women and 35,997 births. We found that $35.8 \%$ of women had facility-based deliveries and 25\% received their recommended 8 ANC contacts (Table 1 ).

Compared to global maternal health-seeking behaviors, women in Nigeria are less likely to deliver in facilities, but more likely to receive their eight recommended ANC contacts $(60 \%$ and $17 \%$ of women globally, respectively). Tables 2 and 3 describe the child-level and quality covariates. 
Table 1. Descriptive Statistics, Mother-Level Outcomes and Covariates, Nigeria, 2008, 2013

\begin{tabular}{|c|c|c|c|c|c|}
\hline & Mean & SD & No. Cases & Min & $\operatorname{Max}$ \\
\hline \multicolumn{6}{|l|}{ Mother-Level Outcomes } \\
\hline Delivery in a health facility & 0.358 & & 12,649 & & \\
\hline WHO Recommended 8 ANC Contacts & 0.250 & & 8,833 & & \\
\hline \multicolumn{6}{|l|}{ Mother-Level Covariates } \\
\hline Wealth, quintiles & 2.798 & 1.415 & & 1 & 5 \\
\hline Maternal education, none (1=yes) & 0.485 & & 17,136 & & \\
\hline Maternal education, primary (1=yes) & 0.204 & & 7,208 & & \\
\hline Maternal education, secondary (1=yes) & 0.252 & & 8,904 & & \\
\hline Maternal education, higher (1=yes) & 0.059 & & 2,085 & & \\
\hline Maternal age, years & 29.338 & 7,354 & & 15 & 49 \\
\hline Marital status (1=married) & 0.926 & & 32,717 & & \\
\hline Urban (1=yes) & 0.323 & & 11,412 & & \\
\hline \multicolumn{6}{|l|}{ Cluster-Level Covariates } \\
\hline Average wealth, quintiles & 2.793 & 1.263 & & 1 & 5 \\
\hline Average education, highest level & 0.874 & 0.773 & & 0 & 3 \\
\hline
\end{tabular}

\begin{tabular}{|l|c|c|c|c|c|}
\hline Table 2. Descriptive Statistics, Child-Level Covariates, Nigeria, 2008, 2013 & Mean & SD & No. Cases & Min & Max \\
\hline \multicolumn{7}{|l|}{ Child-Level Covariates } & 4.118 & 2.677 & & 1 & 18 \\
\hline Birth order & 0.018 & & 648 & & \\
\hline Multiple birth (1 = yes) & 0.505 & & 18,178 & & \\
\hline Child sex (1 = male) & $\mathbf{3 5 , 9 9 7}$ \\
\hline $\mathbf{N}$ \\
Notes: Each observation corresponds to a birth.
\end{tabular}

\begin{tabular}{|c|c|c|}
\hline & Mean & No. Cases \\
\hline \multicolumn{3}{|l|}{ Quality Covariates } \\
\hline Checked weight at pregnancy $(1=$ yes $)$ & 0.232 & 8,351 \\
\hline Checked height at pregnancy (1 = yes) & 0 & 0 \\
\hline Checked blood pressure at pregnancy $(1=$ yes $)$ & 0.557 & 20,050 \\
\hline Took urine sample at pregnancy $(1=$ yes $)$ & 0.495 & 17,819 \\
\hline Took blood sample at pregnancy $(1=$ yes $)$ & 0.495 & 17,819 \\
\hline Told about pregnancy complications ( $1=$ yes) & 0.412 & 14,831 \\
\hline Told where to go for complications ( 1 = yes) & 0.159 & 5,724 \\
\hline Health professional checked after delivery $(1=$ yes $)$ & 0.239 & 8,603 \\
\hline Quality score $(0-1$, percent out of 8$)$ & 0.323 & 11,627 \\
\hline Quality score, prenatal $(0-1$, percent out of 7$)$ & 0.335 & 12,059 \\
\hline $\begin{array}{l}\mathbf{N} \\
\text { Notes: Each observation corresponds to a birth. }\end{array}$ & \multicolumn{2}{|l|}{35,997} \\
\hline
\end{tabular}


In the Nigeria sample, $35.7 \%$ of women report involvement in decision-making regarding their own health care utilization, and $32.7 \%$ were involved in household purchases; $45.4 \%$ in visiting relatives; and $51.2 \%$ were involved in decisions related to money. Overall, $30.7 \%$ of women in Nigeria report involvement in any decision-making. Relatedly, $27.2 \%$ of women believe that a husband is justified in beating his wife for at least one of several reasons (Table 4). Proportions of women's autonomy (measured using decision-making power as proxy) were lower than global estimates (40.1\%), while acceptability of IPVAW was higher in Nigeria (compared to $24.8 \%$ of women globally).

Compared to global positive associations, in Nigeria, the magnitudes of autonomy associations are higher; increased women's autonomy increased the likelihood of facility delivery (Nigeria OR: 1.786, Global OR: 1.3, $p<0.01$ ) and likelihood of receiving eight WHO-recommended ANC contacts (Nigeria OR: 1.537, Global OR: 1.4, $p<0.01$ ). Nigerian associations of acceptability of IPVAW with service utilization opposed global trends; women in Nigeria with higher acceptability of IPVAW scores were more likely to deliver in facilities and obtain eight ANC contacts (ORs: 1,033 and 1.151, respectively, $p<.01$ ) while global estimates showed decreased likelihood of facility delivery and ANC (ORs: 0.911 and 0.797, respectively, $p<.01$ ) (Table 5).

Qualitative data corroborate that acceptance of women's subordinate positions in households renders some unable to independently make health care-seeking decisions.

Spouses/intimate partners, mothers-in-law, and other family members play critical roles determining whether and/or where, the women seek skilled care for ANC, delivery, and postnatal care (PNC). These relationships affect a woman's decision-making ability to adhere to treatment regimens and seek care, given her restricted ability to use her own or her family's money for transport or medications.

\section{"My husband used to tell me to relax and that with time it would go. My mother-in-law sometimes would encourage me and sometimes she would talk as if I'm trying to be lazy, but good friends would encourage me to always visit my doctors for check- up and other treatment." IDI, pre-eclampsia survivor}

\section{Table 4. Distribution of Autonomy and Acceptability of IPVAW Covariates, Nigeria, 2008, 2013}

\begin{tabular}{|l|c|c|}
\hline \multicolumn{2}{|l|}{ Mean } & No. Cases \\
\hline Autonomy & 0.512 & 18,090 \\
\hline Respondent involved in decisions over money (1 = yes) & 0.357 & 12,614 \\
\hline Respondent involved in decisions over own healthcare (1 = yes) & 0.327 & 11,554 \\
\hline Respondent involved in decisions over household purchases (1 = yes) & 0.193 & 6,819 \\
\hline Respondent involved in decisions over daily purchases (1 = yes) & 0.454 & 16,041 \\
\hline Respondent involved in decisions over visiting relatives (1 = yes) & 0 & 0 \\
\hline Respondent involved in decisions over cooking food (1 = yes) & 0.307 & 10,847 \\
\hline Woman autonomy score (0 - 1, percent out of 6) & 0.33 & 11,660 \\
\hline Acceptability of IPVAW & 0.306 & 10,812 \\
\hline Beating justified if wife goes out without telling husband (1 = yes) & 0.275 & 9,716 \\
\hline Beating justified if wife neglects children (1 = yes) & 0.269 & 9,504 \\
\hline Beating justified if wife argues with husband (1 = yes) & 0.178 & 6,289 \\
\hline Beating justified if wife refuses sex (1 = yes) & 0.272 & 9,610 \\
\hline Beating justified if wife burns food (1 = yes) & $\mathbf{3 5 , 3 3 2}$ & \\
\hline Women's acceptability of IPVAW score (0 - 1, percent out of 5) & & \\
\hline N \\
Notes: Each observation corresponds to a woman.
\end{tabular}


Table 5. Odds Ratios of Facility Delivery and Antenatal Care Use, Nigeria, 2008, 2013

\begin{tabular}{|c|c|c|}
\hline Variables & (1) Facility Delivery & $\begin{array}{l}\text { (2) Antenatal Care (WHO } \\
\text { Recommended } 8 \text { Contacts) }\end{array}$ \\
\hline \multicolumn{3}{|l|}{ Main Exposures } \\
\hline Woman's autonomy score & $1.786(1.538-2.074)^{* * *}$ & $1.537(1.300-1.818)^{* * *}$ \\
\hline Women's acceptability of IPVAW score & $1.033(0.924-1.154)$ & $1.151 * * *(1.019-1.300) * * *$ \\
\hline \multicolumn{3}{|l|}{ Covariates } \\
\hline Wealth Quintile 2 & $1.601(1.387-1.847)^{\star * *}$ & $1.368(1.202-1.556) * * *$ \\
\hline Wealth Quintile 3 & $2.112(1.797-2.482) * * *$ & $1.470(1.273-1.698) * * *$ \\
\hline Wealth Quintile 4 & $2.429(2.042-2.891) * * *$ & $1.376(1.162-1.630) * * *$ \\
\hline Wealth Quintile 5 & $3.302(2.753-3.901) * * *$ & $1.735(1.398-2.152) * * *$ \\
\hline Education, Primary & $1.456(1.265-1.675)^{* * *}$ & $1.122(0.976-1.291)$ \\
\hline Education, Secondary & $2.154(1.952-2.378) * * *$ & $1.512(1.337-1.709) * * *$ \\
\hline Education, Higher & $5.107(4.178-6.243) * \star *$ & $2.130(1.665-2.726) * * \star$ \\
\hline Marital Status (1=yes) & $1.486(1.308-1.689) * * *$ & $1.035(0.900-1.191)$ \\
\hline Birth Order & $0.865(0.847-0.883) * * *$ & $0.961(0.942-0.981) * * *$ \\
\hline Child Sex (1 = male $)$ & $1.056(0.997-1.119) * * *$ & $1.018(0.955-1.085)$ \\
\hline Urban (1 = yes) & $1.426(1.219-1.668)^{* * *}$ & $0.977(0.825-1.158)$ \\
\hline Average wealth score & $1.164(1.050-1.290) * * *$ & $1.192(1.070-1.329) * * *$ \\
\hline Average schooling & $2.568(2.235-2.951) * * *$ & $1.362(1.170-1.584) * * *$ \\
\hline Quality score & & $270.8(219.6-333.9) * * *$ \\
\hline Constant & $0.0377(0.0238-0.0596) * * *$ & $0.0329(0.0179-0.0605) * * *$ \\
\hline \multicolumn{2}{|l|}{$\begin{array}{l}\mathbf{N} \\
* * * p<0.01, * * p<0.05, * p<0.1\end{array}$} & 35,209 \\
\hline \multicolumn{3}{|c|}{$\begin{array}{l}\text { Notes: The unit of observation is the birth. Odds ratios are presented with } 95 \% \text { confidence intervals in the parentheses below. Delivery in a facility } \\
\text { (column 1) reports whether the mother delivered the birth in a health facility or not. ANC contacts (column 2) reports whether the mother received at } \\
\text { least } 8 \text { ANC contacts for the birth. Results are from logistic regressions that include cluster, mother, birth, and quality of care controls. Cluster-level } \\
\text { covariates are the average wealth index value of mothers in the cluster, and the average educational attainment of mothers in the cluster. Mother } \\
\text { controls include the household wealth index (in quintiles), educational attainment of the mother (no education, primary, secondary, higher), age of } \\
\text { the mother (in 5-year age groups), mother's marital status, and mother's place of residence (urban/rural). Birth level controls include birth order. } \\
\text { For Column 2, quality of care controls include the 7-point average quality score that was generated for the birth. Standard errors are clustered at the } \\
\text { primary sampling unit (DHS cluster) level. }\end{array}$} \\
\hline
\end{tabular}

The emotional toll of experiencing gender dynamics during pregnancy and postnatally manifest variably in Nigeria. Women's reliance on their spouses/ partners for transportation and financial support limited their ability to access timely care in certain instances. Pregnancy-related expenses deplete families' financial resources, compelling some women to over-work to sustain their households. This influences pregnant women physically and mentally, challenging their ability to rest, receive adequate nutrition, adhere to medications, and maintain a peaceful and supportive home environment while preparing for birth.
"I still informed my husband of what the doctor advised. I was given two weeks to return to the hospital but, started labour before the two weeks given. We have no vehicles around and no money to travel to a tertiary medical center. My husband suggested I went on foot to the maternity near our village, I did. On reaching the hospital, I was attended to by a nurse and she did vaginal examination for me and told that I need to visit a tertiary medical center. I told the nurse it was what we were told but my husband could not afford it. The nurse called a member of the Nigerian Union of Transport Workers Association (NURTWA) Bulkachuwa to come immediately, he came and conveyed me to the hospital." IDI, pre-eclampsia survivor 


\section{CONCLUSIONS \& RECOMMENDATIONS}

Quantitative and qualitative findings suggest that gender dynamics, alongside other factors, affect women's empowerment to seek maternal health services in Nigeria.

Decision-making capacities of women with respect to their health, mobility and use of household finances were observed across methods. Similarly, household power dynamics and normalized IPVAW attitudesthat manifest qualitatively as restricted mobility and dependence on spousal income for instrumental support to access healthcare and transportation-

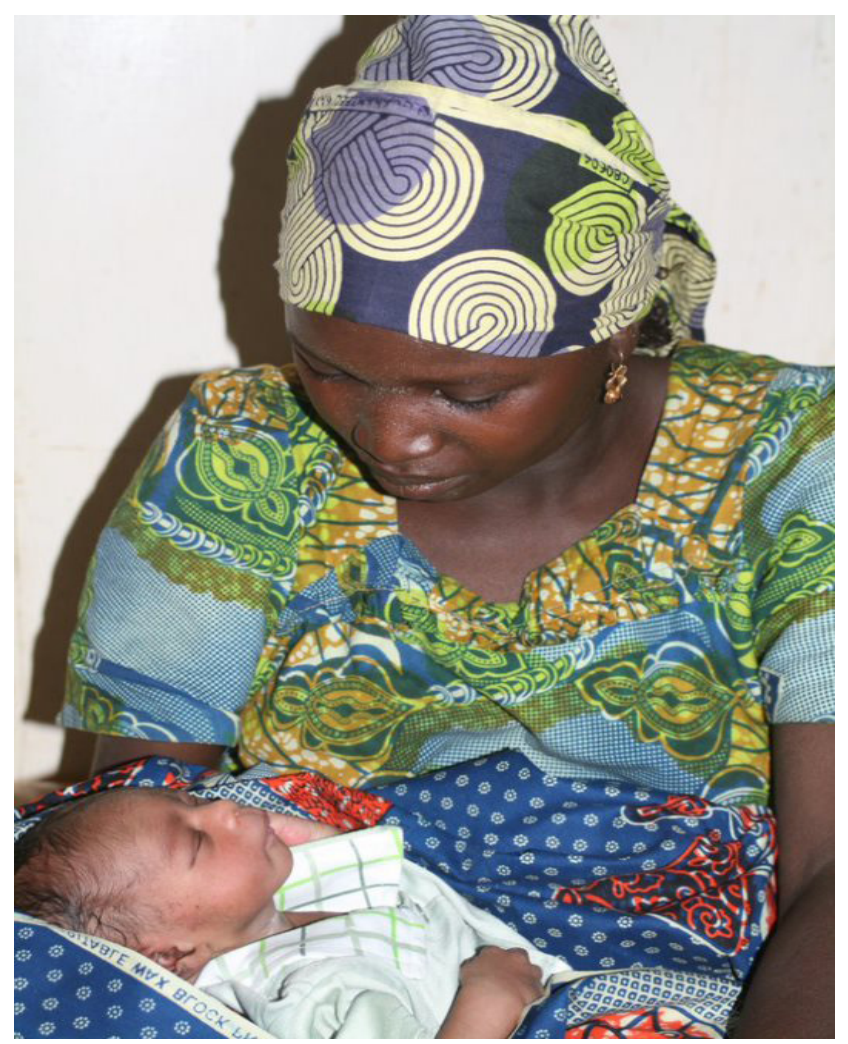

Photo credit: Courtesy of Population Council limit women's ability to reach essential maternal health care.

Less information has emerged organically in qualitative interviews about the influence of IPVAW, though this is likely given the lack of specified focus on this in the formative study. We recommend further research around maternal mental health as it relates to conditions like pre-eclampsia; and explicit gender equity-promoting and socioeconomically supportive policy and programming to enable women to mitigate intra-household dynamics and empower them to use necessary maternal health care.

\section{REFERENCES}

1) Pooja Sripad, Charlotte E Warren, Michelle J Hindin, \& Mahesh Karra, (2018). Assessing the role of women's autonomy and acceptability of intimate partner violence in maternal health-care utilization in 63 low- and middle-income countries. International Journal of Epidemiology, dyy299, https://doi.org/10.1093/ije/dyy299

\section{CONTACT}

Pooja Sripad, Associate, Population Council psripad@popcouncil.org

Charity Ndwiga, Program Officer, Population Council

cndwiga@popcouncil.org

Charlotte Warren, Senior Associate, Population Council cwarren@popcouncil.org

The Ending Eclampsia project seeks to expand access to proven, underutilized interventions and commodities for the prevention, early detection, and treatment of pre-eclampsia and eclampsia and strengthen global partnerships.

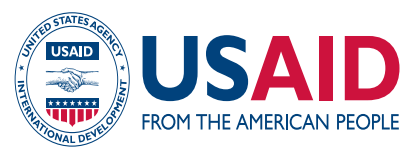

Made possible by the generous support of the American people through the United States Agency for International Development (USAID).
The Population Council conducts research and delivers solutions that improve lives around the world. Big ideas supported by evidence: It's our model for global change. popcouncil.org

๑) 2019 The Population Council, Inc.
POPULATION COUNCIL

Ideas. Evidence. Impact. 